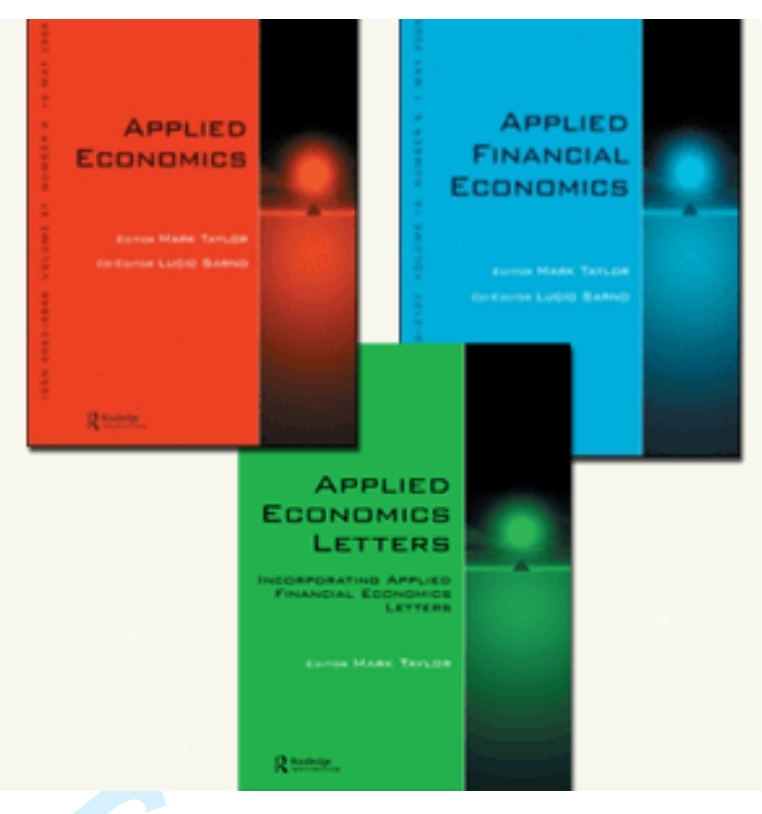

\title{
Testing for long-run convergence across regional house prices in the UK: \\ a pairwise approach
}

\begin{tabular}{|c|c|}
\hline Journal: & Applied Economics \\
\hline Manuscript ID: & APE-2011-0137 \\
\hline Journal Selection: & Applied Economics \\
\hline $\begin{array}{l}\text { Date Submitted by the } \\
\text { Author: }\end{array}$ & 22-Mar-2011 \\
\hline Complete List of Authors: & $\begin{array}{l}\text { Abbott, Andrew; University of Hull, Hull University Business School } \\
\text { De Vita, Glauco; Oxford Brookes University, Business School }\end{array}$ \\
\hline JEL Code: & $\begin{array}{l}\text { C33 - Models with Panel Data < C3 - Econometric Methods: } \\
\text { Multiple/Simultaneous Equation Models < C - Mathematical and } \\
\text { Quantitative Methods, R21 - Housing Demand < R2 - Household } \\
\text { Analysis < R - Urban, Rural, and Regional Economics, R31 - } \\
\text { Housing Supply and Markets < R3 - Production Analysis and Firm } \\
\text { Location < R - Urban, Rural, and Regional Economics }\end{array}$ \\
\hline Keywords: & $\begin{array}{l}\text { Regional convergence, House prices, Pairwise approach, Housing } \\
\text { Market }\end{array}$ \\
\hline
\end{tabular}




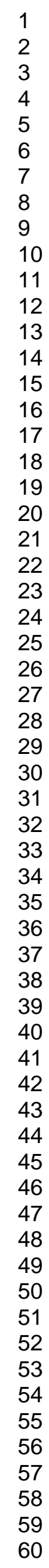

\section{SCHOLARONE ${ }^{m}$ \\ Manuscripts}

7

25

26

27

29

30

32

33

34

35

36

37

39

40

41

42

44

45

46

47

48

49

50

52

53

54

56

57

58

60 


\title{
Testing for long-run convergence across regional house prices in the UK:
}

\section{a pairwise approach ${ }^{*}$}

\author{
Andrew Abbott ${ }^{\mathrm{a},}$ and Glauco De Vita \\ ${ }^{a}$ Business School, University of Hull, Cottingham Road, Hull, HU6 7RX, UK. Email: \\ a.abbott@hull.ac.uk \\ ${ }^{\mathrm{b}}$ Business School, Oxford Brookes University, Oxford, OX33 1HX, UK. Email: \\ gde-vita@brookes.ac.uk. \\ Corresponding author: Email: a.abbott@hull.ac.uk
}

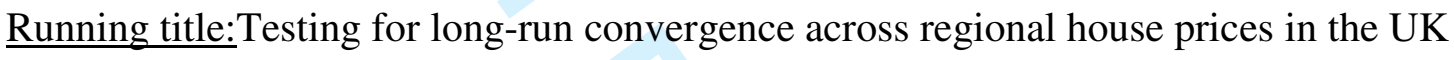

\begin{abstract}
This paper tests for stochastic convergence in UK regional house prices using the recently developed pairwise approach. This approach allows for unit root tests to be conducted on all $N(N-1) / 2$ possible pairs of house price differentials across $N$ regions in the UK, thus avoiding the need to choose a base region or alternative national figure as the benchmark. Using mixadjusted house price data from 1973Q4 to 2008Q4, the main finding is that there is no evidence of long-run convergence among regional house prices or of an equilibrium relationship towards which UK regional house prices have a tendency to gravitate.
\end{abstract}

JEL classification:C33, R21, R31

Keywords:Regional convergence; House prices; Housing Market; Pairwise approach

* For helpful comments on an early draft of this paper we are grateful to Hashem M. Pesaran. 
Testing for long-run convergence across regional house prices in the UK:

\section{a pairwise approach*}

\section{Introduction}

Since the house price boom of the late 1980s, substantial inter-regional differences in UKhouse prices have been the object of continued media attention and public debate. Research interest has followed suit, and a fairly rich research agenda - rekindled at times of housing market appreciations or depreciations - has developed accordingly. The primary, and still unsettled, line of investigation has been that of establishing whether the apparent regional differences in UK house prices are growing steadily over time (divergence hypothesis), exhibit a long-run tendency of convergence (convergence hypothesis) or simply reflect cyclical behaviour, with regional house price gaps widening during house price booms and narrowing during housing market downturns (cyclical gap hypothesis). The analysis is complicated by two additional issues brought to the fore by previous empirical work (see, among others, Alexander and Barrow, 1994; Ashworth and Parker, 1997; Giussani and Hadjimatheou, 1990; Holmes, 2007; Meen, 1999; Peterson et al., 2002; Rosenthal, 1986). The first relates to the possibility of regional segmentation in the UK housing market, with possibly only subgroups of regions forming what could be termed 'house price convergence clubs'. The second issue is the so called 'ripple effect', which describes a tendency for shocks to UK regional house prices to originate in the London region and then spatially diffuse outward from the South East. ${ }^{1}$

\footnotetext{
* For helpful comments on an early draft of this paper we are grateful to Hashem M. Pesaran.

${ }^{1}$ For an insightful discussion of which region ought to be taken as the best candidate to approximate the geographic origin of the ripple (Greater London or the rest of the South East), see Drake's (1995) preliminary analysis.
} 
Despite intense empirical scrutiny, the evidence is still mixed and has yet to provide a conclusive answer as to whether a long-run equilibrium relationship across all regional house prices exists. For example, Macdonald and Taylor (1993) find long-run interregional stability in UK house prices but only limited evidence in support of the ripple effect in the context of weak segmentation of the housing market. Drake (1995) finds that house prices in the North and Scotland exhibit greater divergence from prices in 'the rest of the South East' (RSE, their benchmark region) than do the southern and Midlands regions. The latter regions show a relatively stable 'norm differential', albeit one which is influenced by cyclical factors and is subject to structural changes. As such, he finds no evidence of a ripple effect or of any equilibrating forces of convergence between house prices in the RSE and elsewhere in the UK. By contrast, Cook $(2003,2005)$ unveils the presence of a pattern of asymmetric adjustment between regions, where reversion to equilibrium occurs more rapidly (slowly) during periods in which house prices in the South of England - the Outer South East, the South West and East Anglia -decrease (increase) relative to other regions. More recently, Holmes and Grimes (2008) test convergence by means of a seemingly unrelated regression (SUR) estimator to establish whether the first principal components of the $N$ regional house price differentials (based on regional deviations from the UK average house price) are stationary or not. They find constancy in the long-run house price ratios between all UK regions and also evidence of a ripple effect with respect to house prices originating in London (with the exception of Scotland, whose speed of adjustment towards long-run equilibrium is considerably slower than for all other regions).

By and large, previous empirical work has mainly relied on advances in cointegration or unit root testing procedures to shed light on the nature and degree of convergence in UK regional house prices. Such procedures, however, are typically applied to a common underlying specification of $N$ regional house prices all measured relative to a base region 
(often taken to be the South East or Greater London) or to the ratio of house prices for each region relative to the national (aggregate or average) figure. Such an approach is sensitive to the choice of benchmark (or numeraire), ignores the information in all the other cross price differentials and is subject to a high degree of cross section dependence which has adverse effects on estimation and inference. This paper avoids these problems by employing the recently developed 'pairwise approach' (Pesaran, 2007) to the analysis of long-run convergence. This approach allows for a variety of unit root tests to be conducted on all possible $N(N-1) / 2$ regional house price differentials between pairs of all the $N$ regions of the UK, and estimate, consistently, the proportion of the pairs that are stationary. By allowing for the possibility of forming regional clusters (if any) from the test outcomes, this approach is also ideally suited for investigating the hypothesis of 'club convergence'.

The paper is organized as follows. In Section 2 we offer a rationale for the use of the pairwise approach to the analysis of regional house price convergence by detailing the virtues of this methodology vis-à-vis the statistical techniques employed in previous studies. Section 3 defines multi-regional stochastic convergence and describes the pairwise tests to be conducted. Section 4 discusses data and the empirical results. The final section draws conclusions.

\section{Why the Pairwise Approach?}

Tests of regional house price convergence within a cointegration framework fall within two main approaches. One approach applies system cointegrating techniques directly to the series and tests for the existence of $N$-1 cointegrating vectors among the $N$ regional series. The problem with this approach is that cointegration is necessary but not sufficient if the underlying series are trend stationary. Convergence requires the regional house price series to be cotrended in addition to being cointegrated with the cointegrating vector of the 
form $(1,-1)$. An application of multivariate cointegration analysis can be found in Macdonald and Taylor (1993) who estimate simultaneously $N$-1 linear combinations of UK regional house prices using the Johansen (1991) technique. Although the system cointegration technique that they employ does not require the use of a base region, they do not test whether the house price series that do cointegrate might not be cotrended. In their analysis, therefore, cointegration does not necessarily imply that the house price series are convergent. Furthermore, as they themselves acknowledge, Macdonald and Taylor (1993) did not control for data dependency and relied exclusively on non mix-adjusted indices of (residential) house prices.As noted by Holmes (2007), the use of non mix-adjusted series may be very misleading since such series do not isolate pure price changes from changes in the mixture ofproperties sold each quarter in terms of characteristics such as quality and design.

The second approach tests for unit roots (or stationarity) in $N$-1 regional house price differences with respect to a base region or in the ratio of house prices in a given region relative to the national figure as the numeraire. For example, using the national UK average house price as the benchmark $\left(\mathrm{p}_{\mathrm{n}}\right)$, the house price differentials $\mathrm{p}_{\mathrm{it}}-\mathrm{p}_{\mathrm{nt}}$ for $\mathrm{i}=2,3, \ldots, N$ are tested for unit roots. The significant limitation of this approach is that, irrespective of any transformation of the original series, it is dependent on the choice of the benchmark and could therefore yield misleading results. In an attempt to go beyond standard panel unit root testing procedures, Holmes (2007) and Holmes and Grimes (2008) employ a seemingly unrelated regression (SUR) framework. Although the SUR framework allows for the determination of which series in the panel are responsible for any rejection of the null of joint non-stationarity, this approach is still dependent upon the benchmark of an equilibrium relationship with respect to the UK average house prices series. It follows that, in this context, any evidence of segmentation, with a subset of regions exhibiting divergence from the UK average (as in Holmes, 2007), is also potentially misleading since it relies on the 
assumption of transitivity, according to which these divergent regions are not pairwise cointegrated with any of the remaining regions that are cointegrated with the benchmark (UK) series. Evidently, such an assumption cannot be warranted a priori. For example, in a three region setting with region $\mathrm{n}$ as the benchmark, regions $\mathrm{j}$ and $\mathrm{k}$ could be convergent even if the house price differentials, $\mathrm{p}_{\mathrm{jt}}-\mathrm{p}_{\mathrm{nt}}$ and $\mathrm{p}_{\mathrm{kt}}-\mathrm{p}_{\mathrm{nt}}$ are divergent, namely contain unit roots or deterministic trends. This case would arise if $\Delta \mathrm{p}_{\mathrm{jt}}=\Delta \mathrm{p}_{\mathrm{kt}}$ and $\Delta \mathrm{p}_{\mathrm{jt}} \neq \Delta \mathrm{p}_{\mathrm{nt}}$. Similar concerns apply to Cook's (2003) application of momentum autoregressive (MTAR) unit root tests on the ratio of regional house prices relative to the national figure, in spite of the virtues of these tests in allowing for consideration of stationarity under conditions of asymmetric adjustment.

It is important to emphasise at this point that the pitfalls that surround the use of a base region or national average numeraire are not unique to analyses of long-term convergence that employ unit root or stationarity tests. Even Drake's (1995) application of the Kalman filter is constrained by an econometric specification that hinges upon a UK house price index differential as the benchmark of reference in order to estimate the time varying parameter (his b coefficient) of convergence. ${ }^{2}$

What is required, therefore, is a procedure that allows for the assessment of multi-regional convergence through pairwise convergence across all regional combinations. A procedure which: (i) considers the possibility that the regional house price series that do cointegrate might not be cotrended; and (ii) does not rely on the stringent and potentially misleading assumption of transitivity. The recently developed pairwise approach (Pesaran, 2007) is ideally suited to address the methodological challenges identified above since it allows for testing the unit root and trending properties of all $N(N-1) / 2$ possible house price

\footnotetext{
${ }^{2}$ Drake's (1995) model specification to test for regional house price convergence is [log HPUK - log HPWM $]_{(t)}$ $=a_{t}+b_{t}[\log \text { HPUK }-\log \text { HPSE }]_{(t)}$, where HPUK is the index of UK house prices, HPSE is the index of house prices in the South East, and HPWM is the index of the specified region, in this example the West Midlands. 
differentials, $\mathrm{p}_{\mathrm{it}}-\mathrm{p}_{\mathrm{j}}$, for $\mathrm{i}=1,2, \ldots, N-1$ and $\mathrm{j}=\mathrm{i}+1, \ldots, N$, thus also avoiding the problems inherent in the use of any given benchmark.

\section{Pairwise Tests of UK Regional House Price Convergence}

Two regions' house prices are converging, in a stochastic sense, when, after an exogenous shock, the limit of their expected price differential tends to zero as $\mathrm{T}$ (the number of time periods) increases. House price differentials are therefore transitory. However, if shocks are permanent, the differentials are integrated and diverging. More formally, the analysis that follows draws from Pesaran's (2007)definition of probabilistic convergence which, though originally developed in the context of the growth literature, can be readily applied to house price levels. ${ }^{3}$ Accordingly, regions $\mathrm{i}=1,2, \ldots, N$ are said to converge if for some finite constant $\mathrm{C}$ (reflecting, for example, climate and other area characteristics), and a tolerance probabilitymeasure $\pi>0$,

$$
\operatorname{Pr}\left\{\bigcap_{i=l, \ldots, N-1 ;, j=i+1, \ldots, N}\left|\mathrm{p}_{\mathrm{i}, \mathrm{t}+\mathrm{s}}-\mathrm{p}_{\mathrm{j}, \mathrm{t}+\mathrm{s}}\right|<\mathrm{Cl} \ell_{\mathrm{t}}\right\}>\pi
$$

for $\mathrm{s}$ horizons into the future, $s=1,2, \ldots . ., \infty$. Hence, multi-regional convergence requires pairwise convergence across all regional combinations.

Pairwise tests for each regional pair, $\mathrm{i}$ and $\mathrm{j}$, can be undertaken from a unit root regression of the log house price differential, $\mathrm{d}_{\mathrm{ijt}}=\mathrm{p}_{\mathrm{it}}-\mathrm{p}_{\mathrm{jt}}$ :

$$
\Delta \mathrm{d}_{\mathrm{ijt}}=\alpha_{\mathrm{ji}}+\lambda \mathrm{t}+\beta_{\mathrm{ij}} \mathrm{d}_{\mathrm{ij}, \mathrm{t}-1}+\sum_{\mathrm{s}=1}^{\mathrm{p}_{\mathrm{ij}}} \delta_{\mathrm{ijs}} \Delta \mathrm{d}_{\mathrm{ij}, \mathrm{t}-\mathrm{s}}+\mathrm{v}_{\mathrm{ijt}}
$$

\footnotetext{
${ }^{3}$ Pesaran's (2007) definition is less stringent than the earlier definitions of stochastic convergence developed in the growth literature. Bernard and Durlauf $(1995,1996)$ were the first to define cross-country output convergence in terms of the limit of expected output gaps, with asymptotically perfect convergence said to occur for a group of economies when forecasts of income differences tend to 0. Hobjin and Franses (2000) later introduced the notion of asymptotically relative output convergence whereby forecasts of income differences tend to a non-zero constant.
} 
When $\mathrm{H}_{0}: \beta_{\mathrm{ij}}=0$ cannot be rejected, $\mathrm{p}_{\mathrm{it}}$ and $\mathrm{p}_{\mathrm{jt}}$ are divergent under the null, whereas if $\mathrm{H}_{1}: \beta_{\mathrm{ij}}<0$ holds, the two series are convergent. A further restriction is $\mathrm{H}_{0}: \lambda=0$, the co-trending hypothesis, which indicates that $\mathrm{d}_{\mathrm{ijt}}$ is not trended but stationary around a constant mean. In a cointegrating framework, the above hypotheses represent the cointegrating and co-trending restrictions, respectively. In the present analysis, both of these conditions are tested for, through a specification which, as the one in equation (2), includes both a drift term and a linear trend. Following Pesaran (2007), only stationary pairs that cannot reject the hypothesis of the absence of a significant linear trend are converging pairs. Multi-regional convergence is expected to arise when the fraction of the stationary pairs that satisfy the co-trending restriction is larger than the chosen nominal size of the test.

Two different unit root tests are employed: the standard ADF test and the ADF-GLS test statistic of Elliotet al. (2006). The ADF-GLS test makes use of GLSde-trended data and is expected to have higher asymptotic power and less size than the standard ADF test, through its more efficient estimation of the deterministic components. Two model selection criteria are used to identify the appropriate lag augmentation order: the Akaike Information Criterion (AIC) and the Schwarz Bayesian Criterion (SBC), assuming a maximum lag order of six. As a further sensitivity check, a test with 'stationarity' as the null hypothesis (the KPSS test developed by Kwiatkowskiet al., 1992) is also reported. Under the null hypothesis of stationarity, the KPSS test statistic is given as:

$$
\operatorname{KPSS}_{\mathrm{ijT}}(\ell)=\frac{\mathrm{T}^{-2} \sum_{\mathrm{t}=1}^{\mathrm{T}} \mathrm{s}_{\mathrm{ijt}}^{2}}{\mathrm{~s}_{\mathrm{ijT}}^{2}(\ell)}
$$

where $\mathrm{s}_{\mathrm{ijt}}=\sum_{\ell=1}^{\mathrm{t}} \hat{\mathrm{e}}_{\mathrm{ij} \ell}, \hat{\mathrm{e}}_{\mathrm{ijt}}=\left(\mathrm{d}_{\mathrm{ijt}}-\overline{\mathrm{d}}_{\mathrm{ij}}\right)$ and $\overline{\mathrm{d}}_{\mathrm{ij}}$ is the mean of the house price differential, $\mathrm{d}_{\mathrm{ijt}}$. $\mathrm{s}_{\mathrm{ijT}}^{2}(\ell)$ is the estimate of the long-run variance of $s_{t}$, given by 
$\mathrm{s}_{\mathrm{ijT}}^{2}(\ell)=\frac{1}{\mathrm{~T}} \sum_{\mathrm{t}=1}^{\mathrm{T}} \hat{\mathrm{e}}_{\mathrm{ijt}}^{2}+\frac{2}{\mathrm{~T}}\left[\sum_{\mathrm{k}=1}^{\ell} \mathrm{w}_{\mathrm{k}}\left(\sum_{\mathrm{t}=\mathrm{k}+1}^{\mathrm{T}} \hat{\mathrm{e}}_{\mathrm{ijj}} \hat{\mathrm{e}}_{\mathrm{ij}, \mathrm{t}-\mathrm{k}}\right)\right]$ with the weights defined as

$\mathrm{w}_{\mathrm{k}}=1-\frac{\mathrm{k}}{\ell+1}, \mathrm{k}=1,2, \ldots, \ell$. In the case of the KPSS test, multi-regional convergence can be measured by the fraction of house price differentials that cannot reject the null hypothesis of stationarity and satisfy the co-trending restriction.

Finally, the possibility that house price convergence may hold only for a subgroup or 'club' of regions is considered. In the limit, club convergence tells us if the rejection of convergence is caused by one or a few regions.

\section{Data and Estimation Results}

Data

UK regional house prices are measured using seasonally adjusted quarterly data published by the Halifax Bank and the Nationwide Building Society, the two largest mortgage lenders in the UK over the sample period. Both indices use observations collected from mortgage approvals and thus exclude cash house purchases and mortgage-backed sales from other lenders. These indices were chosen because they have been published for longer periods than available alternatives and adopt a mix-adjusted, volume-weighted price index. The purpose of mix adjustment is to identify pure house price changes, holding constant locational and physical characteristics. This is achieved by hedonic regressions that estimate the market value of the properties' various attributes, from which a synthetic price is placed on each characteristic (Wood, 2005). The indices include all property types from both new housing and transactions germane to the existing stock.

To ensure consistency across the two datasets, the sample period begins in 1983Q1, the first date when the Halifax house price index (HPI) was published, and ends at 2008Q4. 
As can be seen from Figures 1 and 2, that plot the Halifax and Nationwide HPIs, the sample period is sufficiently long to capture two UK housing market cycles: (i) the rise in property prices up to 1990Q1, followed by the slump that finished in 1993Q1; and (ii) the subsequent rise in property prices, peaking in 2007Q1. Data were collected for 12 regions of the UK: Greater London (LN), the South East (SE), the South West (SW), East Anglia (EA), the East Midlands (EM), the West Midlands (WM), the North West (NW), Yorkshire and the Humber $(\mathrm{YH})$, the North (N), Scotland (SC), Wales (WL), and Northern Ireland (NI). Figure 3 shows the exact location of the above regions. Regional classifications across the two datasets are analogous, however, the figures for the South East using the Nationwide HPI are derived from the average house price of the Outer South East and the Outer Metropolitan regions. Price differentials are constructed by subtracting the natural logarithm of the average house price for region $\mathrm{j}$ from the natural logarithm of the average house price for region $\mathrm{i}$, thus $\mathrm{d}_{\mathrm{ijt}}=\ln \left(\mathrm{p}_{\mathrm{it}}\right)-\ln \left(\mathrm{p}_{\mathrm{jt}}\right)$. In total there are $12 \times 11 / 2=66$ distinct pairs, from which the rate of price convergence across UK regions is calculated.

\section{FIGURES 1, 2 and 3 ABOUT HERE}

\section{Results and Discussion}

We begin by considering the unit root properties of the house price differential pairs. Unit root tests are conducted using the full sample of observations, so T=104 from 1983Q12008Q4. Table 1 reports the proportion of pairs for which the unit root hypothesis is rejected using the ADF and ADF-GLS test statistics, and the proportion of pairs that cannot reject the null hypothesis of stationarity from the KPSS test. In total, there are 66 tests used to calculate every rejection frequency and all of them are conducted at the customary $5 \%$ significance level using two information criteria orders of augmentation: the AIC and SBC. Under the hypothesis of non-convergence, the proportion of stationary pairs should be close to the nominal size of the test (Pesaran, 2007; Pesaran et al., 2009). The results uniformly reject the 
convergence hypothesis. The lowest rejection rate is zero from the Halifax ADF test, and the highest rejection rate is $15.15 \%$ from the ADF-GLS-SBC test again using the Halifax dataset. Looking at the results from the ADF test, none of the pairs rejects the unit root hypothesis using the Halifax HPI, while the Nationwide dataset produces rejection frequencies of $1.52 \%$ and $12.12 \%$ using the AIC and SBC. The ADF-GLS test has a higher rejection frequency than the standard ADF test, as expected given its higher power. ${ }^{4}$ For the four cases reported, the average rejection frequency is $7.20 \%$, which while higher than the average of $3.41 \%$ from the ADF, is still very close to the $5 \%$ significance level. Thus, the very limited evidence in favour of convergence emerges from only few pairs and may, therefore, have arisen just by chance. The rejection frequencies are consistent between the two house price indices and across the two information criteria. The average rejection frequency using the Halifax data is $4.54 \%$, and $5.68 \%$ from the Nationwide dataset, while the AIC and SBC produce average rejection frequencies of $3.03 \%$ and $7.57 \%$ respectively. Average lag lengths are quite low. Using the Halifax HPI, the average lag length was 3.87 from the AIC, and 2.56 from the SBC. The corresponding figures using the Nationwide dataset are 3.53 and 1.83 .

Further evidence against the hypothesis of convergence is provided by the KPSS tests. The proportion of pairs that cannot reject the null hypothesis of stationarity is greater than zero in only one case. Using the Nationwide dataset and choosing the lag order from the AIC, the rejection frequency is $1.52 \%$, implying stationarity in the sole case of one house price differential.

\section{TABLE 1 ABOUT HERE}

Next, the analysis sought to identify the convergent pairs by investigating how many pairs are both stationary and satisfy the co-trending restriction. Table 2 shows that the proportion of pairs that can be regarded as stationary around a constant mean is low. The

\footnotetext{
${ }^{4}$ Both Pesaran (2007) and Pesaran et al. (2009) report analogous findings.
} 
proportions of converging pairs for the ADF-GLS test are very similar to the fractions of stationary pairs reported in Table 1 . However, the fractions of converging pairs reported for the standard ADF test are lower. Using the Nationwide HPI with the SBC, the proportion of converging pairs rises to only $1.52 \%$ (one case). As for the KPSS tests, all the results are against the hypothesis of stochastic convergence.

\section{TABLES 2 and 3 ABOUT HERE}

Since unit root tests may exhibit low power when applied to a relatively short data span, to test the robustness of the results presented in Table 2, we undertook additional estimations using an extended Nationwide dataset of house prices, one that starts at 1973Q4 (approximately ten additional years, totalling 141 quarters used for estimation). We also employed the Ng and Perron's (2001) Modified Akaike's Information Criterion (MAIC) as an additional check since the MAIC yields tests with improved size and power properties. ${ }^{5}$ Table 3 presents the results of this exercise, which do not change the conclusions reached heretofore. Convergence rates pertaining to the extended, 36-year sample, range from $0 \%$ using the KPSS test, under all three selection criteria, to $12.12 \%$ using the ADF-GLS test under the AIC. Interestingly, under the MAIC, the proportions of converging pairs are consistently $0 \%$, irrespective of the unit root or stationarity test considered.

So how can evidence of no overall convergence in UK regional house prices be rationalised? First, as convincingly demonstrated by Hwang and Quigley (2006) in their comprehensive study of the effects of national and regional economic conditions on housing markets in metropolitan areas of the U.S.: "housing markets are local, and housing market

\footnotetext{
${ }^{5}$ The MAIC (Ng and Perron, 2001) is defined as $-2(\ell / \mathrm{T})+2(\mathrm{k}+\tau) / \mathrm{T}$, where $\ell$ is the selected bandwidth parameter, $\mathrm{T}$ is the number of time series observations, $\mathrm{k}$ is the chosen lag length and $\tau$ is a modification factor. The MAIC differs from the conventional AIC through the inclusion of $\tau$, which is defined as $\tau=\alpha^{2} \sum_{\mathrm{t}} \mathrm{y}_{\mathrm{t}-1}^{2} / \sigma_{\mathrm{u}}^{2}$, where $\alpha$ is the slope estimate of $\mathrm{y}_{\mathrm{t}-1}$ from the ADF regression and $\sigma_{\mathrm{u}}^{2}$ is the variance of the residual errors from the ADF regression.
} 
outcomes reflect local economic conditions" (p.425). If so, it would be difficult to even contemplate the plausibility of any evidence pointing to 'convergence'(rather than just stationarity) in UK regional house prices without a clearly conceived and cogent theoretical explanation as to why, and how, this finding could emerge in the presence of markedly different regional economic conditions. The UK Department for Business, Enterprise and Regulatory Reform (BERR) has recently produced Regional Economic Performance Indicators (May 2009) that highlight the persistence of significant economic disparities across UK regions, in terms of 'input factors' (such as R\&D expenditure, business start-up rates, business density and educational qualifications), 'output factors' (such as gross value added per head, productivity and employment rates), and 'outcome factors' (for example, wages). Such disparities exist within, as well as among, UK regions, they are large and difficult to bridge. Against this backdrop, our finding of the persistence of house price differentials among UK regions appears to be not only plausible but far less controversial than it may seem prima facie.

Of course, interregional labour migration might have an effect on the demand for housing across regions, with obvious implications for house prices and their potential tendency toward convergence. Yet, also this conceptual link to the direction of interregional labour migration flows would appear to support the evidence presented heretofore. In the UK, where limited frictions hinder the mobility of labour, such flows have traditionally followed the supply of jobs, resulting in a form of arbitrage in the labour market. Since the direction of these flows is not uniform across regions, with a pronounced differential between the labour migration from North-to-South vs. that going the opposite way, the resulting net effect of asymmetric labour migration flows on regional housing markets across the UK is one likely to reinforce existing house price differentials across regions rather than act as an equilibrating mechanism. For example, net interregional labour migration flows into the more 
economically prosperous southern UK regions - such as Greater London and the South East cannot but compound house price differentials vis-à-vis other UK regions by further stimulating job-led demand for housing in the areas that already record the highest house prices.

As noted earlier, a virtue of the pairwise approach is that it allows for the investigation of the hypothesis of club convergence from the test outcomes. This further application of the approach is justified since Pesaran (2007) shows that the rejection frequency does not vary significantly with the number of pairs, $N$, but does tend to rise rapidly with the number of periods, that in the present analysis remains fixed at $\mathrm{T}=104$.

Table 4 reports the rejection frequencies of different regional groupings. Specifically, interest centres on testing for stochastic convergence in house prices across subgroups of English regions: between the South of England, the North of England, the East Midlands and the West Midlands. Moreover, to ascertain whether a wider pool of convergence exists, 'the North' is interacted with the aggregated regions of the Midlands. Finally, a test for convergence adopting a wider definition of 'the South' that includes the East Midlands and East Anglia is undertaken. The latter case is considered since the 'border' of the so-called 'North-South' divide in England has been re-defined recently, and the 'Extended South' now is said to include East Anglia and a large part of the East Midlands (Dorling, 1997).

The analysis reported in Table 4 reports only the results from the ADF-GLS test with orders of augmentation selected using the SBC (due to the high degree of consistency found between unit root test statistics and both model selection criteria). For each 'club' examined, the rate of convergence is calculated from the $N(N-1) / 2$ pairs of regions. For example, convergence of the 'Extended South' club is calculated from the $5 \times 4 / 2=10$ house price differentials pertaining to that regional grouping. Empirical evidence in favour of club convergence appears to be very limited at best. Using the Nationwide dataset, none of the 
clubs examined displays any evidence of convergence, while some evidence of partial convergence can be found using the Halifax HPI. Specifically, one fifth of the relevant pairs converge for the 'Extended South' and 'the North \& Midlands' regions. However, the three remaining cases, 'the North', 'the South' and 'the Midlands' support the divergence hypothesis.

\section{TABLE 4 ABOUT HERE}

Disaggregating the dataset further, Tables 5 and 6 present individual unit root tests for all the bivariate regional combinations under consideration. The bold figures highlight the fairly sporadic events of convergence. Using the Nationwide dataset, only two pairs are found to be convergent: the North-South East and the London-South West differentials. The Halifax HPI provides more evidence in favour of convergence, however, there appears to be no systematic pattern of spatial dependence in terms of contiguity, geographic distance or centre-periphery structure to illuminate as to why some regions' house prices converge over all other bivariate regional combinations. Convergence is found for the North West-Yorkshire and the Humber, Wales-North and North West-Yorkshire and the Humber combinations and for the East Anglia-East Midlands, East Anglia-West Midlands and East Anglia-Wales pairs. The South West region does not appear to converge with any other UK region, while house prices in the South East are found to converge with those of the East Midlands and Wales only. Finally, although the Greater London-North and Greater London-North West price differentials are found to be convergent, a rather interesting finding is the lack of convergence between house prices in Greater London and the South East. The plots for the Greater London-South East house price differential (Figures 4 and 5) corroborate the latter result, suggesting a widening price differential after 1995.

This latter finding is important and deserves further attention not only because the geographic proximity of Greater London and the South East should accentuate spatial and 
temporal house price diffusion (see, for example, Holly et al., 2010), particularly in terms of neighbourhood characteristics (see Meen, 2001), but also because Greater London and the South East are the two most economically successful regions of the UK, and the two regions that have the highest house prices. One might therefore argue that arbitrage could have been expected to lead to convergence at least in the case of these two southern regions, especially given that the supply of jobs is high in both, with bilateral flows of job matching taking place. Yet, consistent with our previous rationalisation, the persistence of house price differentials between Greater London and the South East may be due to the contiguity of these two regions, as a result of which labour mobility translates into higher 'commuting' rather than 'migration' flows, with no consequent equilibrating effect on the respective housing markets. Indeed, 'commuting' rather than 'migrating' across these regions may tend to reinforce rather than reduce the existing house price gap. Evidence from previous literature supports this supposition. Jackman and Savouri (1992a, 1992b, 1996) considered the implication of the commuting/migrating trade-off on the determinants of migration across UK regions and found that fixed costs are much greater for migrating, while commuting costs strongly increase with distance.Contiguity, therefore, implies that the decision of where to live can be made more independently from the decision of where to work. In the case of contiguous regions, where the commuting option is relatively cheap, people who live in the regionwith somewhat lower housing costs would be inclined to stay living there and commute to the contiguous region with higher house prices for work (see also evidence from Murphy et al., 2006). Similarly, people who already live in the regionwith somewhat higher house prices may also be inclined to stay living there - thus avoiding the considerable fixed costs of relocation ${ }^{6}$ - and commute to the contiguous region with lower house prices for work.

\footnotetext{
${ }^{6}$ In the UK, 'stamp duty' is charged depending on the purchase price of the property. The current (2010) stamp duty rates are $1 \%$ for properties over $£ 175,000$ to $£ 250,000,3 \%$ for properties over $£ 250,000$ to $£ 500,000$, and $4 \%$ for properties with a purchase price in excess of $£ 500,000$. Additional fixed costs include estate agent
} 


\section{TABLES 5and6ABOUT HERE \\ FIGURES4and5ABOUT HERE}

The results of the present analysis are in stark contradiction to those obtained by Macdonald and Taylor (1993). They found strong evidence for long-run cointegrating relationships (up to nine cointegrating vectors) in regional house prices, seemingly driven by the convergence adjustment process of two large groups of regions, with Greater London, the South East, the South West and East Anglia forming one club, and the West and East Midlands, the North, the NorthWest, Yorkshireand the Humber, Wales and Scotland forming another. The comparison acts as a reminder of the necessity to use appropriate data (they relied exclusively upon nonmix-adjusted series of regional house prices), to employ a sufficiently large sample for the analysis of long-run convergence (their sample period was limited to 18 years, ending in 1979) and a suitable testing methodology (they did not ensure the satisfaction of the co-trending restriction hence failing to establish whether stationary linear combinations were, in fact, convergent).

Several previous studies also found evidence in favour of the existence of a 'ripple effect' (see Cook, 2003, 2005; Holmes, 2007; and Holmes and Grimes, 2008). Although the present study did not set out to test the ripple effect and was not concerned with the analysis of short-run movements in regional house prices, the finding of no overall long-run house price convergence across all the regions of the UK implies that any ripple-like effects in regional house prices reflect, at best, transitory movements rather than the (symmetric or asymmetric) adjustment process towards an equilibrium relationship of house prices across all the UK regions. As such, the results of the present analysis, are more in line with the findings presented by Drake (1995), who found no evidence of 'significant equilibrating

charges (for sellers only), valuation and survey costs, and legal costs that include a solicitor's fee, as well as Land Registry and Local Authority search fees. 
forces' between regional house prices, and who dismissed the 'ripple effect' as no more than a series of leads and lags in house price movements across regions. It should also be borne in mind that the findings of the studies cited above are indiscriminately affected by a model specification which, being based on regional house price ratios relative to the UK aggregate figure as the benchmark, is subject to considerable crosssection dependence with adverse effects for estimation and inference.

\section{Conclusions}

The primary aim of this paper was to test for stochastic convergence across regional house prices in the UK using the recently developed pairwise approach. This approach avoids the problems inherent in estimation of the typical model specification found in previous studies, a specification dependent upon the choice of a base region or national house price figure as the benchmark of reference. By allowing for the possibility of forming regional clusters from the test outcomes, implementation of this methodology also permitted the investigation of the hypothesis of 'club convergence', i.e. that house price convergence may hold only for a subgroup or 'club' of regions.

The empirical analysis of the unit root and trending properties of log house price differentials across all the $N$ regions in the UK over the period 1983Q1-2008Q4, offers no evidence in support of overall convergence. Hence, there appears to be no equilibrium relationship towards which UK regional house prices have a tendency to gravitate. The hypothesis of 'club convergence' is also not supported, with only two subgroups of UK regions (the 'Extended South', and the 'North' with the 'Midlands') displaying some evidence of partial convergence. Confirmatory, bivariate, pairwise tests corroborate the rather sporadic events of convergence. These results hold across the use of two different datasets of mix-adjusted house price series (Halifax and Nationwide house price indices), three different 
unit root (stationarity) teststatistics (the ADF, ADF-GLS and KPSS), and two alternative model selection criteria (AIC and SBC).Robustness tests undertaken using an extended sample of house pricesthat starts at 1973Q4, and an additional modified Akaike's information criterion (MAIC) with improved size and power properties, confirm the reliability of the results presented.

The overall finding that substantial inter-regional differences in UK house prices have a tendency to persist, has important implications in terms of, for example, labour mobility, migration and commuting patterns, and social inequality across UK regions, and should prove useful in the evaluation of national as well as region-specific housing policy.

In interpreting the findings of the present study, two final caveats are in order.First, following much of the literature that investigates regional house price convergence, the analysis reported here is empirical rather than theoretical. The aim of this paper was to test for stochastic convergence in house prices across UK regions using state-of-the-art econometric techniques whilst making no attempt to identify the determinants of regional house prices. Yet, the plausibility of our findings - rationalised in terms both of the existing regional economic disparities and of the direction of the flows regulating labour market arbitrage vis-à-vis the regional supply and demand of housing - is strong. This means that should future evidence pointto the convergence of UK regional house prices, work producing such evidence will be burdened with the additional onus of devising a theory that in addition to fitting to the statistical properties of the data is capable of nesting our conceptual explanation.Second, investigation of pairwise convergence is essentially an analysis germane to the long-run. The extent to which short-run house price adjustments or transitory contagion effects occur across regions, and the specific dynamics of such short-run movements, were beyond the scope of this study. 


\section{References}

Alexander, C. and Barrow, M. (1994) Seasonality and co-integration of regional house prices in the UK,Urban Studies,31, 1667-1689.

Ashworth, J. andParker, S.C. (1997)Modelling regional house prices in the UK,Scottish Journal of Political Economy,31, 225-246.

Bernard, A.B. and Durlauf, S.N. (1995) Convergence in international output,Journal of Applied Econometrics, 10, 97-108.

Bernard, A.B. and Durlauf, S.N.(1996)Interpreting tests of the convergence hypothesis,Journal of Econometrics, 71, 161-174.

Cook, S. (2003) The convergence of regional house prices in the UK,Urban Studies, 40, 2285-2294.

Cook, S. (2005)Regional house price behaviour in the UK: Application of a joint testing procedure,Physica A,345, 611-621.

Dorling, D. (1997) The north-south divide: where is the line?Available at http://sasi.group.shef.ac.uk/maps/nsdivide/index.html.

Drake, L. (1995) Testing for convergence between UK regional house prices, Regional Studies,29, 357-366.

Elliot, G., RothenbergT.J. andStock J.H. (1996) Efficient tests for an autoregressive unit root,Econometrica,64, 813-836.

Giussani, B. and Hadjimatheou, G. (1990) Econometric model of regional house prices in the UK, Discussion Paper No. 90/02, Kingston University, London.

Hobjin, B. andFranses,P.H. (2000) Asymptotically perfect and relative convergence of productivity,Journal of Applied Econometrics, 15, 59-81.

Holly, S., Pesaran,M.H. and Yamagata,T. (2010)Spatial and temporal diffusion of house prices in the UK,Journal of Urban Economics, forthcoming. 
Holmes, M.J. (2007) How convergent are regional house prices in the United Kingdom? Some new evidence from panel data unit root testing,Journal of Economic and Social Research,9, 1-17.

Holmes, M.J. andGrimes, A. (2008) Is there long-run convergence among regional house prices in the UK?,Urban Studies,45, 1531-1544.

Hwang, M. andQuigley, J.M. (2006) Economic fundamentals in local housing markets: evidence from U.S. Metropolitan Regions,Journal of Regional Science,46, 425-453.

Jackman, R. andSavouri, S. (1992a) Regional migration versus regional commuting: the identification of housing and employment flows,Scottish Journal of Political Economy,39, 272-287.

Jackman, R. andSavouri, S. (1992b)Regional migration in Britain: an analysis of gross flows using NHS central register data,Economic Journal,102, 1433-1450.

Jackman, R. andSavouri, S.(1996)Regional migration and the hiring function: an examination of distance and contiguity effects in Great Britain, 1975-92,in: Schettkat, R. (ed.), The Flow Analysis of Labour Markets.London: Routledge.

Johansen, S. (1991) Estimation and hypothesis testing of cointegration vectors in Gaussian vector autoregressive models,Econometrica,59, 1551-1580.

Kwiatkowski, D., Phillips,P.C.B., Scmidt, P. and Shin Y. (1992)Testing the null hypothesis of stationarity against the alternative of a unit root,Journal of Econometrics,54, 159178.

Macdonald, R. and Taylor,M.P. (1993) Regional house prices in Britain: long run relationships and short run dynamics,Scottish Journal of Political Economy,40, 43-55.

Mackinnon, J.G. (1996) Numerical distribution functions for unit root and cointegration tests,Journal of Applied Econometrics,11, 601-618. 
Meen, G. (1999) Regional house prices and the ripple effect: anew interpretation,Housing Studies, 14, 733-753.

Meen, G. (2001)Modelling spatial housing markets: theory, analysis and policy,Kluwer, Boston.

Murphy, A., Muellbauer,J. andGavin,C. (2006)Housing marketdynamicsand regional migration in Britain, CEPR Discussion Paper No. 5832.

Ng,S. andPerron, P. (2001)Lag length selection and the construction of unit root tests with good size and power,Econometrica,69, 1519-1554.

Pesaran, H.M. (2007)Apair-wise approach to testing for output and growthconvergence, Journal of Econometrics,138, 312-355.

Pesaran, H.M., Smith,R.P., Yamagata, T. and Hvozdyk, L. (2009) Pairwise tests of purchasing power parity,Econometric Reviews, 28, 495-521.

Peterson, W., Holly,S. andGaudoin, P. (2002)Further Work on an Economic Model of the Demand for Social Housing. Department for the Environment, Transport and the Regions,London.

Regional Economic Performance Indicators (2009)Regional Economic Performance Indicators: Regional Competitiveness and State of the Regions. Department for Business Enterprise \& Regulatory Reform,London.

Rosenthal, L. (1986)Regional house price interactions in the UK, 1975-81: Across-spectral analysis,Applied Economics, 18, 1011-1023.

Wood, R. (2005) A Comparison of UK Residential House Price Indices, Paper No. 21, Bank for International Settlements. 
Table 1 Proportion of pairs rejecting the null hypothesis of a unit root (ADF, ADF-GLS) or not rejecting the null of stationarity (KPSS)

\begin{tabular}{ccccc}
\hline $\begin{array}{c}\text { House price } \\
\text { index }\end{array}$ & $\begin{array}{c}\text { Order selection } \\
\text { criterion }\end{array}$ & ADF & ADF-GLS & KPSS \\
\hline Halifax & AIC & 0 & 3.03 & 0 \\
Nationwide & SBC & 0 & 15.15 & 0 \\
& AIC & 1.52 & 7.57 & 1.52 \\
& SBC & 12.12 & 3.03 & 0
\end{tabular}

Note: ADF is the standard Augmented Dickey-Fuller test, ADF-GLS is the GLS-detrended Dickey-Fuller test of Elliotet al. (2006), KPSS is the KPSS test for stationarity of Kwiatkowski et al. (1992). Unit root tests (tests for stationarity) are conducted for every house price differential at the 5\% significance level using the Mackinnon (1996) critical values for the ADF and ADF-GLS tests, and the Kwiatkowski et al. (1992) critical values for the KPSS test. There are $12 \times 11 / 2=66$ distinct pairs of regions and T=104 from the sample period 1983Q1 to 2008Q4. Orders of augmentation are chosen by the AIC and SBC, assuming a maximum lag order of six.

Table 2 Proportion of pairs that are both stationary and have a non-significant time trend i.e. converging pairs

\begin{tabular}{ccccc}
\hline $\begin{array}{c}\text { House price } \\
\text { index }\end{array}$ & $\begin{array}{c}\text { Order selection } \\
\text { criterion }\end{array}$ & ADF & ADF-GLS & KPSS \\
\hline Halifax & AIC & 0 & 3.03 & 0 \\
Nationwide & SBC & 0 & 15.15 & 0 \\
& AIC & 0 & 6.06 & 0 \\
& SBC & 1.52 & 3.03 & 0 \\
\hline
\end{tabular}

Note: The proportion of all pairs that are converging is calculated from those house price differentials that reject the null hypothesis of a unit root (cannot reject the null of stationarity) and have an insignificant time trend (the co-trending restriction). ADF is the standard Augmented Dickey-Fuller test, ADF-GLS is the GLS-detrended Dickey-Fuller test of Elliotet al. (2006), KPSS is the KPSS test for stationarity of Kwiatkowski et al.(1992). The nominal size of the unit root test is set at 5\% with the co-trending restriction being rejected whenever the t-ratio of the time trend coefficient exceeds the $5 \%$ critical values.

Table 3 Proportion of pairs that are both stationary and have a non-significant time trend i.e. converging pairs (extended sample, 1973Q4-2008Q4)

\begin{tabular}{ccccc}
\hline $\begin{array}{c}\text { House price } \\
\text { index }\end{array}$ & $\begin{array}{c}\text { Order selection } \\
\text { criterion }\end{array}$ & ADF & ADF-GLS & KPSS \\
\hline Nationwide & AIC & 10.61 & 12.12 & 0 \\
& SBC & 7.58 & 6.06 & 0 \\
& MAIC & 0 & 0 & 0 \\
\hline
\end{tabular}

Note: The proportion of all pairs that are converging is calculated from those house price differentials that reject the null hypothesis of a unit root (cannot reject the null of stationarity) and have an insignificant time trend (the co-trending restriction). ADF is the standard Augmented Dickey-Fuller test, ADF-GLS is the GLS-detrended Dickey-Fuller test of Elliotet al. (2006), KPSS is the KPSS test for stationarity of Kwiatkowski et al.(1992). The MAIC is the $\mathrm{Ng}$ and Perron (2001) modified Akaike's information criterion, defined as $-2(\ell / \mathrm{T})+2(\mathrm{k}+\tau) / \mathrm{T}$, where $\ell$ is the selected bandwidth parameter, $\mathrm{T}$ is the number of time series observations, $\mathrm{k}$ is the chosen lag length and $\tau$ is a modification factor.The nominal size of the unit root test is set at 5\% with the co-trending restriction being rejected whenever the t-ratio of the time trend coefficient exceeds the $5 \%$ critical values. 
Table 4 Convergence clubs

\begin{tabular}{|c|c|c|c|}
\hline House price index & Convergence club & Regions & Rate of convergence \\
\hline \multirow{5}{*}{ Halifax } & The South & LN, SE, SW & 0 \\
\hline & Extended South & LN, SE, SW, EA, EM & 20 \\
\hline & The North & $\mathrm{N}, \mathrm{NW}, \mathrm{YH}$ & 0 \\
\hline & The North \& Midlands & N, NW, YH, EM, WM & 20 \\
\hline & Midlands & EM, WM & 0 \\
\hline \multirow[t]{5}{*}{ Nationwide } & The South & LN, SE, SW & 0 \\
\hline & Extended South & LN, SE, SW, EA, EM & 0 \\
\hline & The North & $\mathrm{N}, \mathrm{NW}, \mathrm{YH}$ & 0 \\
\hline & The North \& Midlands & N, NW, YH, EM, WM & 0 \\
\hline & Midlands & EM, WM & 0 \\
\hline
\end{tabular}


Table 5 Bivariate unit root tests using the Halifax HPI

\begin{tabular}{|c|c|c|c|c|c|c|c|c|c|c|c|c|}
\hline & $\mathrm{LN}$ & SE & SW & EA & EM & WM & $\mathrm{N}$ & $\mathrm{YH}$ & NW & WL & $\mathrm{NI}$ & SC \\
\hline $\mathrm{LN}$ & - & & & & & & & & & & & \\
\hline SE & -2.316 & - & & & & & & & & & & \\
\hline SW & -1.906 & -2.464 & - & & & & & & & & & \\
\hline EA & -1.821 & -1.629 & -1.944 & - & & & & & & & & \\
\hline EM & -1.932 & -3.087 & -2.738 & -3.055 & - & & & & & & & \\
\hline WM & -2.738 & -2.989 & -2.471 & -3.205 & -1.637 & - & & & & & & \\
\hline $\mathrm{N}$ & -3.166 & -2.791 & -2.809 & -2.180 & -2.127 & -2.819 & - & & & & & \\
\hline YH & -2.516 & -2.293 & -2.682 & -2.569 & -2.199 & -2.030 & -2.001 & - & & & & \\
\hline NW & -3.071 & -2.203 & -2.748 & -2.126 & -2.570 & -3.202 & -1.639 & -3.048 & - & & & \\
\hline WL & -2.930 & -3.112 & -2.864 & -3.206 & -2.269 & -1.945 & -3.235 & -1.582 & -2.457 & - & & \\
\hline NI & -2.473 & -2.577 & -2.817 & -2.948 & -2.710 & -2.163 & -2.682 & -2.553 & -2.011 & -2.709 & - & \\
\hline $\mathrm{SC}$ & -2.644 & -2.713 & -1.891 & -2.203 & -1.705 & -1.985 & -2.089 & -2.822 & -2.101 & -2.522 & -2.362 & - \\
\hline
\end{tabular}

Note: Figures are values of the ADF-GLS test for a unit root, with order of augmentation chosen using the SBC. Both intercept and linear trend are included in the regression. Bold figures indicate those pairs which are converging i.e. the house price differential is stationary and has a non-significant time trend.

Table 6 Bivariate unit root tests using the Nationwide HPI

\begin{tabular}{|c|c|c|c|c|c|c|c|c|c|c|c|c|}
\hline & $\mathrm{LN}$ & SE & SW & EA & EM & WM & $\mathrm{N}$ & $\mathrm{YH}$ & NW & WL & $\mathrm{NI}$ & $\mathrm{SC}$ \\
\hline $\mathrm{LN}$ & - & & & & & & & & & & & \\
\hline $\mathrm{SE}$ & -2.089 & - & & & & & & & & & & \\
\hline SW & -2.284 & -1.484 & - & & & & & & & & & \\
\hline EA & -2.437 & -2.117 & -2.257 & - & & & & & & & & \\
\hline $\mathrm{EM}$ & -2.311 & -2.588 & -2.033 & -1.786 & - & & & & & & & \\
\hline WM & -2.156 & -2.257 & -1.693 & -2.629 & -1.766 & - & & & & & & \\
\hline $\mathrm{N}$ & -2.724 & -3.054 & -3.026 & -2.750 & -1.635 & -1.699 & - & & & & & \\
\hline YH & -2.842 & -2.540 & -2.736 & -2.732 & -1.722 & -1.215 & -2.479 & - & & & & \\
\hline NW & -3.128 & -2.455 & -2.678 & -2.264 & -1.536 & -2.235 & -1.898 & -2.069 & - & & & \\
\hline WL & -2.477 & -2.358 & -2.389 & -2.306 & -1.285 & -1.429 & -1.551 & -2.968 & -1.551 & - & & \\
\hline NI & -2.032 & -1.979 & -1.955 & -2.622 & -2.069 & -2.363 & -2.832 & -2.092 & -2.832 & -2.588 & - & \\
\hline $\mathrm{SC}$ & -2.142 & -2.123 & -2.003 & -2.412 & -1.422 & -1.774 & -1.422 & -2.131 & -1.990 & -1.606 & -2.492 & - \\
\hline
\end{tabular}

Note: Figures are values of the ADF-GLS test for a unit root, with order of augmentation chosen using the SBC. Both intercept and linear trend are included in the regression. Bold figures indicate those pairs which are converging i.e. the house price differential is stationary and has a non-significant time trend. 


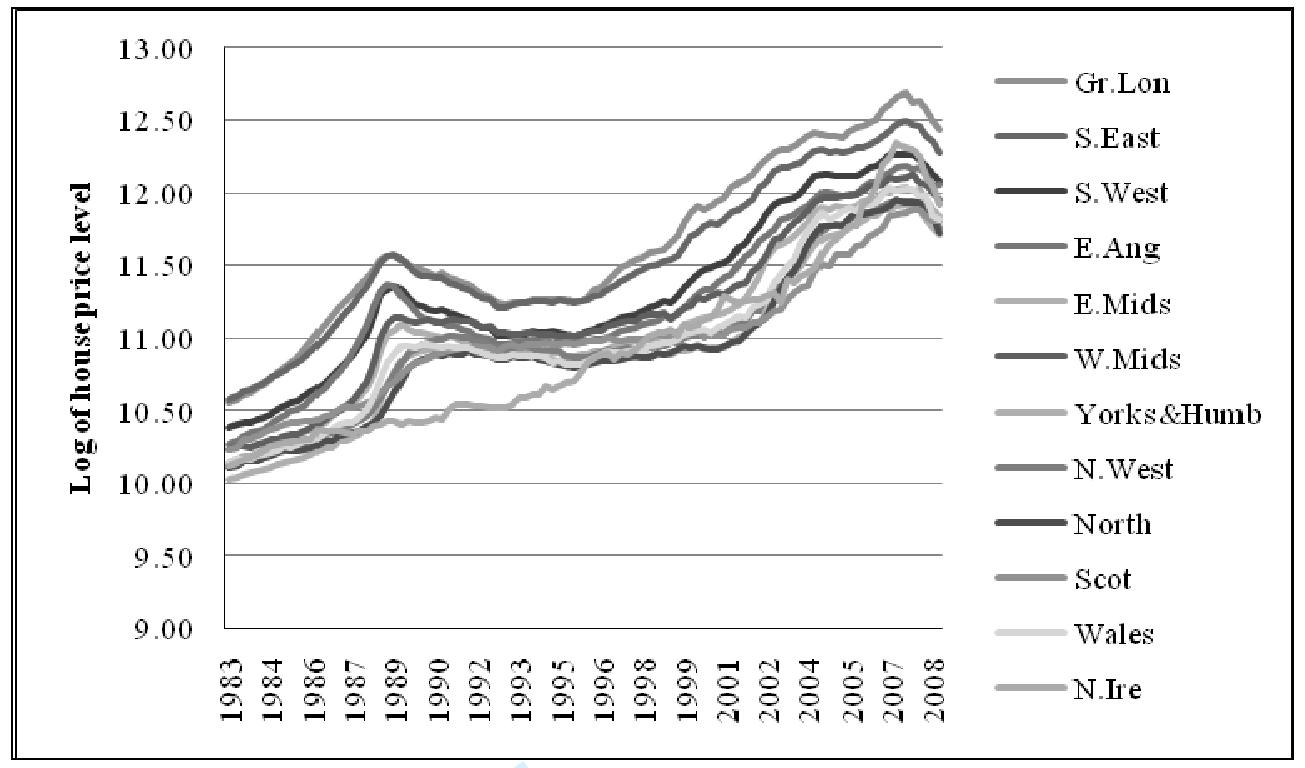

Figure 1 Log of regional house price level (Halifax HPI)

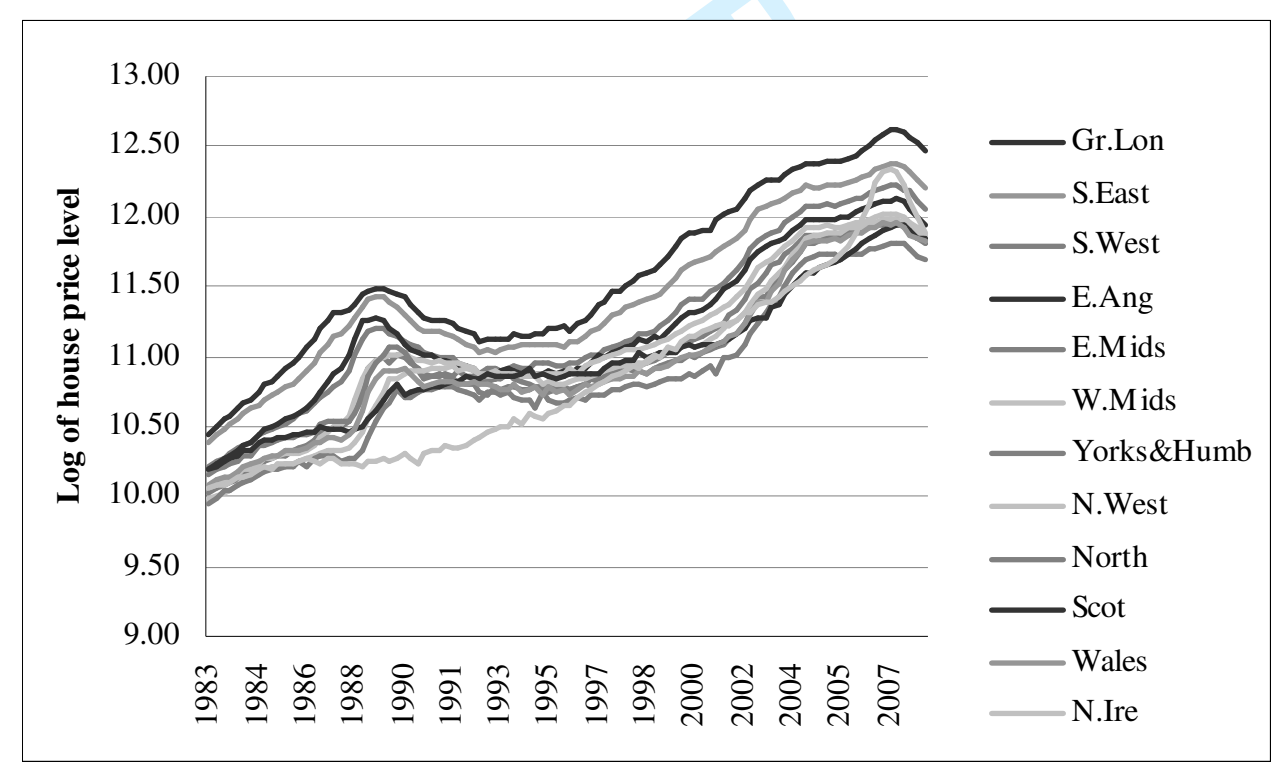

Figure 2 Log of regional house price level (Nationwide HPI) 


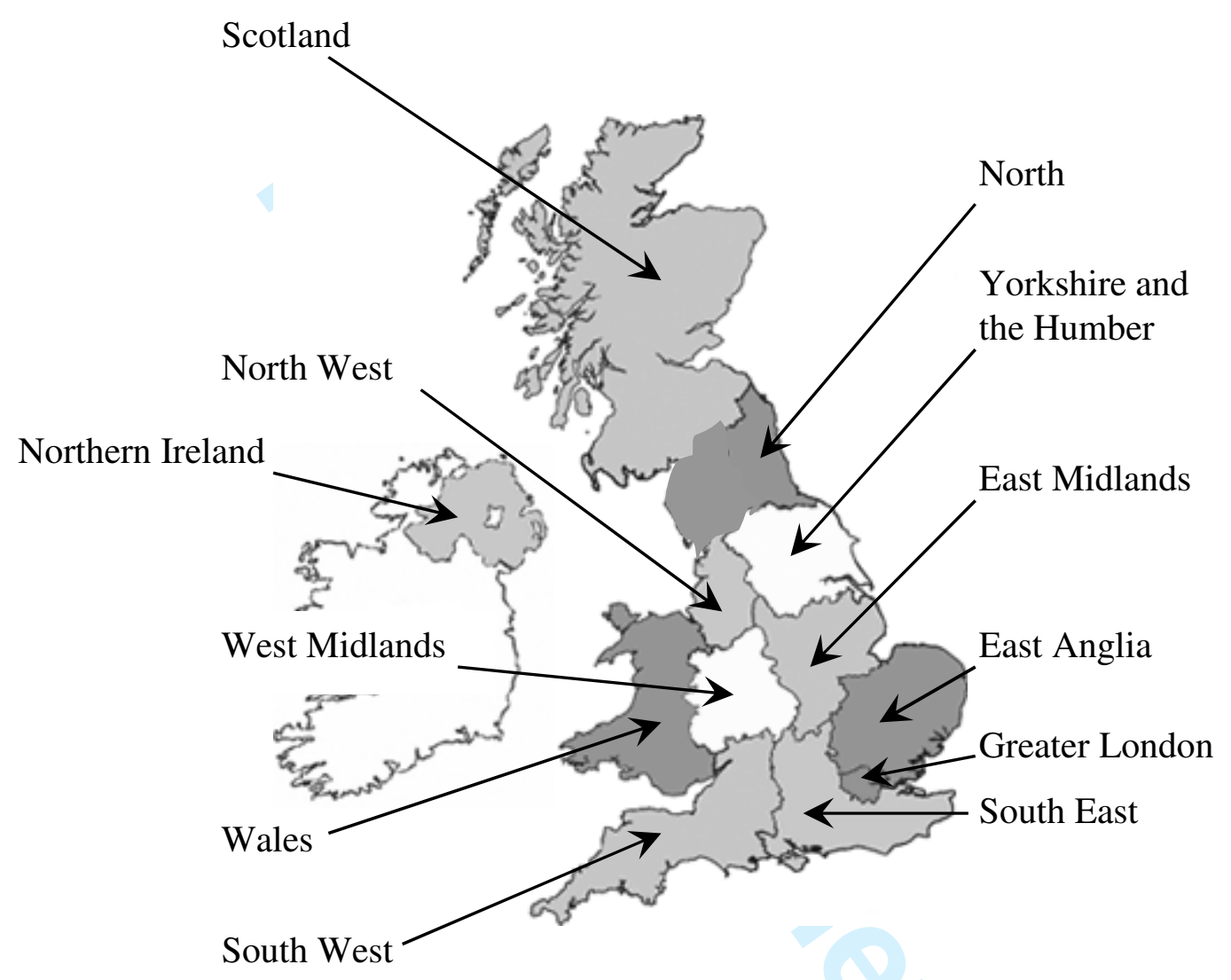

Source: able.co.uk

Note: The regions come from the definitions provided by the Halifax House Price Index. To ensure strict comparability, for the Nationwide house price index, the series for the South East region is derived from the house prices indices of both the Outer Metropolitan and Outer South East regions.

Figure 3 Map of UK regions 
Figure 4 Log house price differential for Greater London-South East (HalifaxHPI)

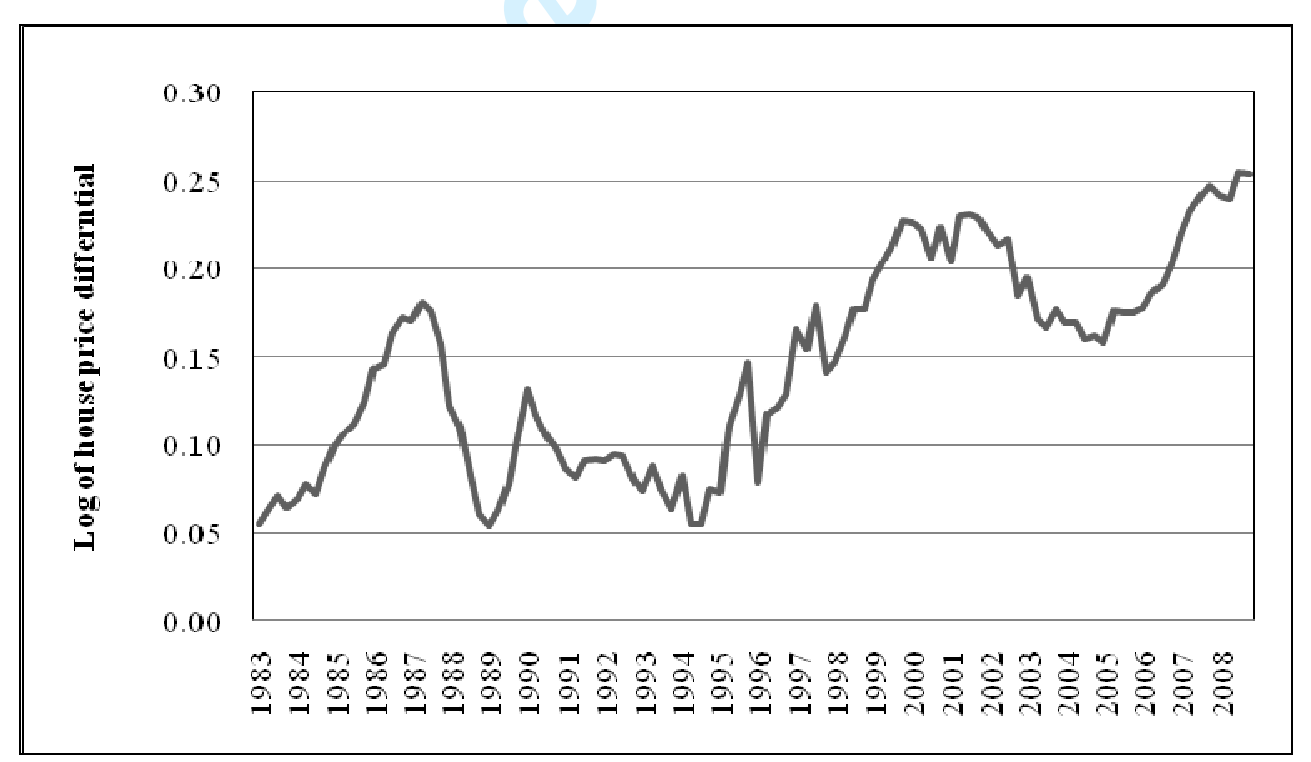

Figure 5 Loghouse price differential for Greater London-South East (Nationwide HPI) 